\title{
Physical, Microbial, and Chemical Quality of Hot-Air-Dried Persimmon (Diospyros kaki) Chips during Storage
}

\author{
Rebecca R. Milczarek (D, ${ }^{1}$ Ana M. Vilches, ${ }^{1}$ Carl W. Olsen, ${ }^{1}$ Andrew P. Breksa, ${ }^{1}$ \\ Bruce E. Mackey, ${ }^{2}$ and Maria T. Brandl ${ }^{3}$ \\ ${ }^{1}$ Healthy Processed Foods Research Unit, United States Department of Agriculture, Agricultural Research Service, Albany, \\ CA 94710, USA \\ ${ }^{2}$ Pacific West Area, United States Department of Agriculture, Agricultural Research Service, Albany, CA 94710, USA \\ ${ }^{3}$ Produce Safety and Microbiology Research Unit, United States Department of Agriculture, Agricultural Research Service, \\ Albany, CA 94710, USA
}

Correspondence should be addressed to Rebecca R. Milczarek; rebecca.milczarek@ars.usda.gov

Received 20 September 2019; Revised 4 February 2020; Accepted 18 February 2020; Published 31 March 2020

Academic Editor: Elena González-Fandos

Copyright $\odot 2020$ Rebecca R. Milczarek et al. This is an open access article distributed under the Creative Commons Attribution License, which permits unrestricted use, distribution, and reproduction in any medium, provided the original work is properly cited.

\begin{abstract}
Recent efforts have been made to develop hot-air-dried chips as a value-added product for persimmon fruit (Diospyros kaki). However, the long-term quality of this product and its dependence on processing conditions and packaging type have not yet been explored. Hence, in this work, chips were prepared from "Hachiya" persimmon fruit in 2 ways: 2 mm thickness fruit slices, hot-airdried for 5 hours (Preparation 2-5), and $6 \mathrm{~mm}$ slices, dried for 10 hours (Preparation 6-10). The dried chips were then packaged into 2 bag types (plastic zip-top and metallized polyethylene terephthalate (Met-PET) with desiccant packets), stored under ambient conditions, and sampled for moisture-related, microbial, texture, and chemical quality traits throughout the 1-year storage study. It was found that-with the exception of a marked decrease in ascorbic acid (vitamin C) - all 4 Preparation/ Packaging combinations yielded products that maintained acceptable color, microbial, nutritional, and textural quality throughout the entire study. Compared to Preparation 2-5 chips, Preparation 6-10 chips generally had lower contents of healthy nutrients-antioxidant compounds, ascorbic acid, and carotenoids. Evidence of invertase activity was found for Preparation 6-10 chips but not for Preparation 2-5 chips. For both preparations, the contents of ascorbic acid and carotenoids experienced timedependent decreases. Plastic zip-top bags and Met-PET bags with desiccant packets performed equally well as packaging for most of the quality metrics tracked during this study. Overall, this work has demonstrated that hot-air-drying of persimmon slices is a promising approach to create a value-added product with at least one year of shelf-life.
\end{abstract}

\section{Introduction}

Persimmon (Diospyros kaki) is an orange-colored tree fruit that has seen a steady growth in worldwide production, increasing more than $50 \%$ in the 10 years from 2007 to 2017 [1]. Still, the fruit is rarely consumed in the United States; it is sold in fresh form primarily in farmers' markets in the State of California and nationwide in Asian specialty grocery stores. Thus, several recent efforts have been made to increase the marketability of persimmon fruit by the development of hot-air-dried chips as a value-added product
[2-4]. One hallmark of persimmons that could potentially be an impediment to consumer acceptance of a hot-air-dried product is certain persimmon cultivars' astringent mouthfeel. Fortunately, hot-air-drying of some (but not all) astringent cultivars results in low to no astringency in dried persimmon chips, and the popular cultivar "Hachiya" is one that responds favorably to hot-air-drying [3].

Although hot-air-dried "Hachiya" persimmon chips have been well received by consumers, the chips' stability during storage has not yet been fully explored. The quality of dried fruit during storage depends on many factors, 
including raw materials, processing conditions, Packaging, use of additives, and temperature of storage [5]. Nutrients of interest, such as ascorbic acid (vitamin C), degrade more slowly in dried products compared to their fresh counterparts, but still do degrade over time and should be evaluated to determine a reasonable marketable shelf-life for the product [6]. Recent work on storage of microwave-hot-airdried persimmon chips in various packaging materials has indicated that storage in polyamide bags flushed with nitrogen preserved the chips' quality well [7], but similar investigation of hot-air-dried (without microwave use) persimmon chips is lacking.

There is reason to believe that significant changes in the nutritional composition and mouthfeel of hot-air-dried persimmon chips may occur during long-term storage. This is due to learning from the processing and storage of hoshigaki-a traditional East Asian Preparation of astringent persimmon as an intermediate moisture product. The multiweek, ambient air-drying involved in this process is known to affect the flavor of hoshigaki in a desirable way. During drying, the characteristic astringent mouthfeel of the fruit decreases, and a powdery white coating of sugar (primarily glucose and fructose) develops on the exterior of the product [8]. Recent work has been done to characterize the shelf-life of hoshigaki (water activity $\left(a_{\mathrm{W}}\right) 0.77-0.83$ ) at different storage temperatures [9]. However, low-moisture $\left(a_{\mathrm{W}}\right.$ near 0.45 ), hot-air-dried persimmon chips have not yet been explored in this way, and the sugar bloom phenomenon has not been investigated for this product. Lastly, it is also not known how different hot-air-drying conditions affect the microbial stability of the freshly dried and longterm-stored product. Thus, this aspect-along with changes in the nutrition and texture of the product during storage-was explored in the current study.

\section{Materials and Methods}

2.1. Fruit Material, Preparation, Packaging, and Storage. Approximately $95 \mathrm{~kg}$ of fresh persimmon fruit (cultivar "Hachiya") were purchased from a local grower at a farmers' market in Richmond, CA, USA, in November 2017 (it should be noted that "Hachiya" persimmons can have seeds, but all the fruit used for this study were seedless). The fruit all had a uniform deep orange color and were ripe but not mellow (i.e., the fruit were firm enough to slice cleanly). Mean CIE $L^{*}, a^{*}$, and $b^{*}$ color values of the exterior of 5 randomly selected fruit were 64.5 (s.d. 3.9), 22.9 (s.d. 1.8), and 48.8 (s.d. 0.6 ), respectively, as measured with a CM-700D colorimeter (Konica Minolta Sensing Americas, Inc.). The mean puncture firmness of these fruit was $1.7 \mathrm{~kg}$ (s.d. 1.0), as measured with a Magness-Taylor penetrometer. The persimmons were stored in a $2^{\circ} \mathrm{C}$ refrigerator until needed for drying.

Food-contact surfaces were first washed with tap water and dish soap and then sanitized in a $200 \mathrm{ppm}$ chlorine solution. To remove surface soil, the fruit were rinsed with tap water. Fruit were then sliced to one of two thicknesses $(2 \mathrm{~mm}$ or $6 \mathrm{~mm}$ ) on a commercial slicer (Model 1612P, Hobart, Troy, OH, USA). The stem- and blossom-end portions of the fruit were discarded. The slices were arranged in a single layer on the trays of commercial dehydrators (Model 2924T, Excalibur Dehydrator, Sacramento, CA, USA) and dried at $63^{\circ} \mathrm{C}\left(145^{\circ} \mathrm{F}\right)$ for 5 hours for the $2 \mathrm{~mm}$ slices (hereafter, "Preparation 2-5") and for 10 hours for the $6 \mathrm{~mm}$ slices ("Preparation 6-10"). The 2 drying preparations were based on guidance for consumers about how to dry persimmons at home [10]. The dried slices were conditioned for 24 hours at ambient temperature $\left(20^{\circ} \mathrm{C}\right)$ in sealed polycarbonate plastic boxes (a separate box for each Preparation) to allow moisture to distribute evenly among all the slices in a batch. Due to the large quantity of dried persimmon chips needed for the storage study and the limited capacity of the dehydrators, samples were dried in several batches over the course of 9 days, and all the samples of the same preparation were pooled together before packaging. The $5^{\text {th }}$ day of drying was considered to be "Day 0" for the purpose of this study.

Packaging type can have an important effect on the quality of dried foods over their typical shelf-life. Aluminum laminate pouches have been found to be superior to polyethylene plastic pouches for long-term storage of nuts $[11,12]$, owing to the former packaging material's higher oxygen barrier properties. However, consumers are unlikely to have access to aluminum laminate pouches and the requisite heat-sealing equipment; readily available plastic zip-top bags may be the only packaging available to this group. Thus, both types of packaging were investigated in the current work. Samples were packed into one of two types of containers: plastic zip-top bags (hereafter, "Plastic") and heat-sealed metallized polyethylene terephthalate bags ("Met-PET"). Approximately $800 \mathrm{~g}$ of dried persimmon slices were packed into each bag. Each Met-PET bag contained desiccant packets (WiseMini ${ }^{\circledR}$, Wisesorbent Technology, Marlton, NJ, USA) in addition to the persimmon slices. The desiccant packets were included at a loading rate of 19 packets per 2-gallon $(7570 \mathrm{cc}$ ) bag, per the manufacturer's instructions [13]. The Plastic treatment was intended to simulate a storage method that would be inexpensive and readily available to consumers; the Met-PET treatment was intended to simulate commercial packaging of dried fruit products.

This storage study took place over the course of 52 weeks (1 year). Bags were stored at ambient temperature $\left(20^{\circ} \mathrm{C}\right)$ in opaque storage tubs. At each time point, one bag of each of the 4 Preparation $\times$ Packaging combinations was randomly selected for analysis. Analyses occurred at 0, 2, 5, 10, 16, 25, and 52 weeks, as measured from Day 0 (described above).

Table 1 summarizes the levels of the three controlled variables of this study. It should be noted that the Packaging variable does not apply to the Time 0 samples, as these samples cannot be considered to be "packed" in either bag type immediately after drying.

\subsection{Moisture-Related and Color Analyses}

2.2.1. Moisture Content. The moisture content was measured gravimetrically in a vacuum oven (Precision Scientific, Model 524). Five aluminum moisture cups containing 
TABLE 1: Controlled variables of this storage study.

\begin{tabular}{lc}
\hline Variable & Levels \\
\hline Preparation & $2-5(2 \mathrm{~mm}$ thickness, dried for 5 hours $) ;$ \\
Packaging & $6-10(6 \mathrm{~mm}$ thickness, dried for 10 hours $)$ \\
Time (weeks) & Plastic and Met-PET \\
\hline
\end{tabular}

washed sand and a small glass rod were prepared for each sample a day in advance and dried in a convection oven at $75-80^{\circ} \mathrm{C}$. Persimmon chips from each storage condition were ground in a coffee grinder to break up the chips for analysis of moisture content and $a_{\mathrm{W}}$. A tare weight was recorded for each cup, and five to six grams of the ground sample material was placed in each cup. After the addition of the material, a gross weight was recorded. The sample wet weight was the difference between the gross weight and the tare weight. The moisture cups were placed in a vacuum oven for $22-24$ hours at $70^{\circ} \mathrm{C}$ and dried under vacuum. After drying, the sample dry weight was recorded. The moisture content (wet basis) of the sample was calculated as follows:

$$
\left(\frac{\text { sample wet weight }- \text { sample dry weight }}{\text { sample dry weight }}\right) \times 100 \text {. }
$$

2.2.2. Water Activity. $a_{\mathrm{W}}$ was measured on the AquaLab, 4TE (Meter Food). Working from the same ground sample used for moisture content, a small sample of dried persimmon was removed and placed in a water activity cup, and the cup was then placed in the water activity chamber. The meter was set up to read measurements at $25^{\circ} \mathrm{C}$. For each sample, there were five replicates.

2.2.3. Color. The color of persimmon chips was measured in CIE $L^{*}, a^{*}$, and $b^{*}$ coordinates using the CM-700D colorimeter (Konica Minolta Sensing Americas, Inc.). Five random chips were taken from each stored bag. Each whole chip was placed on a white target mask, and measurements were taken at 5 different spots on the chip. The 5 measurements were averaged and recorded. The measurements were taken under these conditions on the colorimeter: D65 illuminant, $10^{\circ}$ observer, $6 \mathrm{~mm}$ aperture.

To compare the change in color from Time 0 to subsequent time points, the total color difference $(\Delta E)$ was calculated by the following equation:

$$
\Delta E=\left[\left(L^{*}-L_{0}^{*}\right)^{2}+\left(a^{*}-a_{0}^{*}\right)^{2}+\left(b^{*}-b_{0}^{*}\right)^{2}\right]^{1 / 2},
$$

where $\Delta E$ is the total color difference between a Time $=\mathrm{x}$ sample and the corresponding Time $=0$ sample; $L^{*}$ and $L_{0}^{*}$ are the lightness of a sample at Time $=\mathrm{x}$ and Time $=0$, respectively; $a^{*}$ and $a_{0}^{*}$ are the redness of a sample at Time $=\mathrm{x}$ and Time $=0$, respectively; and $b^{*}$ and $b_{0}^{*}$ are the yellowness of a sample at Time $=\mathrm{x}$ and Time $=0$, respectively.

2.3. Microbial Analyses. At each sampling time during the drying period, ten replicate slices of each thickness and from each packaging type were processed for plate counts to assess culturable aerobic bacteria and fungi present on the slices. In order to recover the bacterial and fungal cells from the dried slices, these were placed individually in $10 \mathrm{ml}$ potassium phosphate buffer $(10 \mathrm{mM}, \mathrm{pH}$ 7.0) in a WhirlPak bag, incubated at $4^{\circ} \mathrm{C}$ for one hour to soften the fruit tissue, and then homogenized for $1 \mathrm{~min}$ at medium speed in a MiniMix 100 lab blender (Interscience, Woburn, MA, USA). The resulting suspensions were plated undiluted by hand onto $10 \%$ Tryptic Soy Agar (TSA) containing $100 \mu \mathrm{g} / \mathrm{ml}$ cycloheximide to prevent fungal growth and allow for enumeration of bacterial colonies only and onto Dichloran Rose Bengal Chloramphenicol (DRBC) Agar for enumeration of yeasts and molds. Suspension aliquots of 200 and $500 \mu \mathrm{l}$ were spread per plate from samples tested at weeks 0 through 5 , and 10 through 52 weeks of drying, respectively. Plates were incubated at $28^{\circ} \mathrm{C}$ for $48 \mathrm{~h}$ and then at $24^{\circ} \mathrm{C}$ for four days before bacterial and fungal colony-forming units (CFUs) were enumerated. These plate counts were used to estimate the total number of bacteria or fungi on each slice sample. Based on this approach, the detection limit was 50 and $20 \mathrm{CFU}$ per slice for sampling during weeks 0 through 5 , and 10 through 52, respectively. For samples for which the plate counts were below the detection limit, the value of 0 was assigned a value of 1 . This was done to better reflect the high probability that no chip could be truly sterile. All plate count values were log-transformed before statistical analysis.

2.4. Instrumental Texture Analyses. Texture profile analysis (TPA) and shear analysis were used for the instrumental texture analysis of the dried persimmon chips. Both of these analyses were conducted on TA-163 XTPlus 100 Texture Analyzer (Stable Micro Systems Ltd., UK) equipped with a $100 \mathrm{~kg}$ load cell. Both of these methods are described in detail in our previous work [14]. Briefly, five persimmon chips were chosen from each bag. For TPA, a cork borer was used to excise one tissue sample, approximately $7 \mathrm{~mm}$ in diameter, from each of the 5 chips that were chosen. Using calipers, the height and diameter of each sample were measured and recorded. The sample was subjected to a double compression cycle using a TA-11ss probe (stainless steel probe, $25.4 \mathrm{~mm}$ in diameter). The compression speed was $1.67 \mathrm{~mm} / \mathrm{s}$, and samples were compressed to $50 \%$ of their measured height.

The shear analysis was also done on 5 random chips from each bag. A custom-made stainless steel blunt shear blade of $1 \mathrm{~mm}$ thickness was used for the shear test. The shear blade sliced through an area approximately $15 \mathrm{~mm}$ long. The thickness of the persimmon chip was measured before each analysis within this testing area. The speed of the blade was $1.67 \mathrm{~mm} / \mathrm{s}$, and it was programmed to cut $150 \%$ of the measured height.

For both tests, the results were graphed in a force-distance curve. Eight texture metrics were derived from TPA (Hardness1, Energy1, Hardness2, Energy2, Cohesiveness, Springiness, Chewiness, and Resilience) and three were derived from shear analysis (MaxLoad, Toughness, and PeakCount). Detailed formulae for these metrics and their associated qualitative aspects can be found in our previous work [14]. 


\subsection{Chemical Analyses}

2.5.1. Reagents. L-ascorbic acid, ethylenediaminetetraacetic acid disodium salt dihydrate (EDTA), sodium carbonate, sulfuric acid (Certified ACS), vanillin (Certified ACS plus), hexanes, acetone, and methanol (high-performance liquid chromatography (HPLC) grade) were obtained from Fisher Scientific Chemicals (Fair Lawn, NJ). Malic acid, citric acid, fumaric acid, glucose, fructose and sucrose standards, m-phosphoric acid, gallic acid, 2,6-di-tert-butyl-4-methylphenol (BHT), cinnamic acid, 6-hydroxy-2,5,7,8-tetramethylchroman-2-carboxylic acid (Trolox), 2,2'-azinobis (3ethyl-benzothiazoline-6-sulfonic acid) diammonium salt (ABTS), catechin hydrate $(98 \%+)$, and potassium persulfate were supplied by Sigma-Aldrich (St. Louis, MO).

Ethanol, 190 proof, was obtained from Pharmco-AAPER (Brookfield, CT). $\beta$-Carotene was supplied by Alfa Aesar (Tewksbury, MA). Tris(2-carboxyethyl) phosphine hydrochloride (TCEP-HCl) was obtained from Hampton Research (Aliso Viejo, CA). Folin-Ciocalteu's phenol reagent $(2 \mathrm{~N})$ was purchased from MP Biomedicals Inc. (Solon, OH), and potassium phosphate monobasic was obtained from JT Baker (Phillipsburg, NJ). Water was deionized to $\geq 18.1 \mathrm{M} \Omega$ / $\mathrm{cm}$ resistance using a Barnstead NANOpure Deionization System (Dubuque, IA). For HPLC analysis, water was further filtered through a $0.22 \mu \mathrm{m}$ type HA membrane filter (Millipore, Billerica, MA) prior to use.

2.5.2. Material Preparation. For each bag, approximately $50 \mathrm{~g}$ of dried persimmon chips was first broken into small pieces (approx. 1-6 $\mathrm{mm}$ ) by hand. The pieces were ground in a coffee grinder (Model W10327169A, Kitchen Aid, Benton Harbor, MI) until small particles (approx. 0.2-1 mm) were obtained.

2.5.3. Organic Acids including Vitamin C (Ascorbic Acid). $0.5000 \pm 0.0010 \mathrm{~g}$ of ground sample was extracted twice with $12 \mathrm{~mL}$ of extract solution of $5 \% \mathrm{~m}$-phosphoric acid, $1 \mathrm{mM}$ EDTA, and $5 \mathrm{mM}$ TCEP-HCl into a $30 \mathrm{~mL}$ Teflon centrifuge tube. Sample was homogenized using a Polytron PT3100 homogenizer (Kinematica AD, Littau-Luzern, Switzerland) at the speed of $11000 \mathrm{rpm}$ for $2 \mathrm{~min}$ under argon and then centrifuged at $17,200 \mathrm{~g}$ at $4^{\circ} \mathrm{C}$ for $30 \mathrm{~min}$. The supernatants were collected into a $25 \mathrm{~mL}$ volumetric flask and brought to $25 \mathrm{~mL}$ using extract solution. The solution was filtered using a PVDF $(0.22 \mu \mathrm{m}, 33 \mathrm{~mm})$ syringe filter before the analysis in the HPLC system.

The chromatographic separation was performed using a Waters 2695 Separation Module (Milford, MA) coupled to a 996 PDA detector. The system was equipped with a Prevail Organic Acid $3 \mu(150 \times 4.6 \mathrm{~mm})$ column (Grace Discovery Sciences, Deerfield, IL). The column was maintained at $30^{\circ} \mathrm{C}$ with an isocratic mobile phase consisting of $25 \mathrm{mM}$ potassium phosphate monobasic solution ( $\mathrm{pH} 2.50)$ set at $1.0 \mathrm{~mL} / \mathrm{min}$. Quantification was based on external calibration curves of malic $(220 \mathrm{~nm}, 15-1000 \mathrm{mg} / \mathrm{L})$, citric $(220 \mathrm{~nm}$, $15-1000 \mathrm{mg} / \mathrm{L})$, ascorbic $(240 \mathrm{~nm}, 1.5-100 \mathrm{mg} / \mathrm{L})$, and fumaric $(220 \mathrm{~nm}, 0.225-15 \mathrm{mg} / \mathrm{L})$ acids.
2.5.4. Sugars. $1.000 \mathrm{~g} \pm 0.001 \mathrm{~g}$ of ground sample was combined with $50 \mathrm{~mL}$ methanol: water $(80: 20)$ in a blender (Classic, Oster, USA) and homogenized for 15 seconds. The homogenized solution was centrifuged at 12,000g for $7 \mathrm{~min}$ at $4^{\circ} \mathrm{C}$ using a Sorvall RC 5 Plus centrifuge (Thermo Scientific, Waltham, MA) and the supernatant collected. The supernatant was filtered through a Millex-GV $(0.22 \mu \mathrm{m}$, $13 \mathrm{~mm}$ ) syringe filter and diluted with filtered water to $1: 4$ prior to HPLC analysis (in addition to the sugar analysis, the extraction solution collected was used for the colorimetric assays of AOX, TSP, and condensed tannins, described later).

The chromatographic separation was performed using a Waters 2695 Separation Module (Waters, Milford, MA, USA) and a Luna $5 \mu \mathrm{m}$ NH2 $100 \AA(250 \times 4.6 \mathrm{~mm}$ id $)$ column (Phenomenex, Torrance, CA). The column was maintained at $30{ }^{\circ} \mathrm{C}$ with an isocratic mobile phase of acetone and water $(83: 17)$ set at $1 \mathrm{~mL} / \mathrm{min}$. Detection of carbohydrates was accomplished using a Sedex-55 (SEDERE, France) evaporative light scattering detector $\left(35^{\circ} \mathrm{C} \pm 1{ }^{\circ} \mathrm{C}, 3.1 \pm 0.1\right.$ bar $\mathrm{N} 2$, and gain set at 6). Quantification was based on external calibration curves of glucose $(100-4000 \mathrm{mg} / \mathrm{L})$, fructose $(100-4000 \mathrm{mg} / \mathrm{L})$, and sucrose $(100-4000 \mathrm{mg} / \mathrm{L})$. Maltose $(500 \mathrm{mg} / \mathrm{L})$ was included as an internal standard.

2.5.5. Antioxidant Activity (AOX). Assay was performed on the persimmon extracts in methanol: water $(80: 20)$, and absorbance measurements were made using a SpectraMax Plus 384 spectrophotometer (Molecular Devices, Sunnyvale, CA). A Trolox calibration curve $(0-150 \mu \mathrm{g} / \mathrm{mL})$ was used and results were calculated in Trolox equivalents per gram sample (TEAC mg/g) using SoftMax ${ }^{\circledR}$ Pro (version 5.0.1, Molecular Devices Corp.). The assay was carried out in triplicate and results are reported as averages in milligrams of Trolox equivalents per gram of dried sample.

For the ABTS antioxidant activity assay, the method of Breksa and Manners [15] was used. Briefly, ABTS was dissolved in water (HPLC grade) to a $7 \mathrm{mM}$ concentration. ABTS radical cation was produced by reacting ABTS stock solution with $2.45 \mathrm{mM}$ potassium persulfate and allowing the mixture to stand in the dark at room temperature for $16 \mathrm{~h}$ before use. For the determination of antioxidant capacity, the ABTS radical solution was diluted with methanol to an absorbance of $0.70 \pm 0.01$ at $734 \mathrm{~nm}$. $2 \mathrm{~mL}$ of diluted ABTS radical solution was added to $100 \mu \mathrm{L}$ of the sample extract, control, or standard solution. After incubation for $6 \mathrm{~min}$ at $20^{\circ} \mathrm{C}$ while protected from light, the absorbance was measured at $734 \mathrm{~nm}$. Ascorbic acid $(0.05 \mathrm{mg} / \mathrm{mL})$ and BHT $(0.250 \mathrm{mg} / \mathrm{mL})$ were used as positive controls and cinnamic acid $(1 \mathrm{mg} / \mathrm{mL})$ as a negative control.

2.5.6. Total Soluble Phenolics (TSP). The Folin-Ciocalteu method [16] for the colorimetric estimation of total polyphenols was used, with some modifications. Trolox $(500 \mu \mathrm{g} /$ $\mathrm{mL})$ and BHT $(500 \mu \mathrm{g} / \mathrm{mL})$ were used as positive controls, and cinnamic acid $(1.0 \mathrm{mg} / \mathrm{mL})$ was used as a negative control. The sample extracts prepared in $80: 20$ methanol: water were used for this analysis. All sample extracts, 
control, and standard solutions $(100 \mu \mathrm{L})$ were diluted with $1.5 \mathrm{~mL}$ of water and mixed with $100 \mu \mathrm{L}$ of Folin-Ciocalteu's phenol reagent $(1 \mathrm{~N})$. The reaction was protected from light, and after $5 \mathrm{~min}$ incubation at room temperature, $300 \mu \mathrm{L}$ saturated sodium carbonate solution $(75 \mathrm{~g} / \mathrm{L})$ was added. Solutions were mixed and incubation was continued as described above for $2 \mathrm{~h}$. Absorbance was measured at $765 \mathrm{~nm}$ with a SpectraMax Plus 384 spectrophotometer (Molecular Devices, Sunnyvale, CA, USA). Quantification was based on a standard curve generated with $25,50,100$, $200,300,400$, and $500 \mathrm{mg} / \mathrm{L}$ of gallic acid. Values were calculated using SoftMax ${ }^{\circledR}$ Pro (version 5.0.1, Molecular Devices Corp.) and reported as mg gallic acid equivalents (GAE) per gram of dried material (mg GAE/g DW). The assay was carried out in triplicate and results are reported as averages.

2.5.7. Percent (\%) Tannins. Of the phenolic compounds quantified in the TSP assay, a portion are tannins (compounds most relevant to persimmon product flavor and nutrition) and the remainder are other phenolic compounds of lower molecular weight. Percent tannin content (as a portion of TSP content) determinations were based on the sample treatment method of $\mathrm{Wu}$ and Hwang [17] with some modifications. In brief, high-molecular-weight tannins were removed from persimmon extracts via ultrafiltration and the TSP contents of the treated and untreated samples were used to calculate the percent tannin content (equation (3)). Sample extracts prepared in methanol: water $(80: 20)$ were diluted $1: 1$ with deionized water, and $1 \mathrm{~mL}$ of the diluted extract was applied to the upper layer of a $100 \mathrm{~K}$ MWCO Centricon ${ }^{\circledR}$ centrifugal filter device that was previously rinsed with methanol: water $(40: 60)$. The centrifugal filter devices were centrifuged at ambient temperature for $50 \mathrm{~min}$ at 1,000x using a Sorvall RC 5 Plus centrifuge (Thermo Scientific, Waltham, MA).

$$
\% \text { tannin content }=\left(\frac{(\text { untreated }- \text { treated })}{\text { untreated }}\right) * 100 \% \text {. }
$$

2.5.8. Condensed Tannins. Of the soluble tannins present in the persimmon extract, some are condensed (nonhydrolyzable) and some are hydrolyzable. The quantity of condensed tannins is of interest because it is these compounds that are responsible for the astringent sensation in persimmons [17]. Prior to analysis for condensed tannins, samples were filtered through a $0.22 \mu \mathrm{m}$ PVDF syringe filter (Fisher Scientific Ltd.). The vanillin- $\mathrm{H}_{2} \mathrm{SO}_{4}$ method [18] for the colorimetric estimation of condensed tannins was adapted following the suggestions of Karaman et al. [19]. In a $2 \mathrm{~mL}$ polypropylene 96 -well plate, blanks ( $80: 20$ methanol : water), samples, or standards $(400 \mu \mathrm{L})$ were mixed with $500 \mu \mathrm{L}$ of $1 \%$ vanillin in $\mathrm{MeOH}(\mathrm{w} / \mathrm{v})$. A replicate set of samples were mixed with $500 \mu \mathrm{L}$ of $\mathrm{MeOH}$ and used to account for background absorbance. A solution of $25 \%$ concentrated sulfuric acid in $\mathrm{MeOH}(\mathrm{v} / \mathrm{v}, 300 \mu \mathrm{L})$ was added to each well. A $400 \mu \mathrm{L}$ portion of each assay was transferred to the well of a glass 96-well plate (Zinsser Analytical, Frankfurt, Germany) and the absorbance measured at $500 \mathrm{~nm}$ with a Molecular Devices SpectraMax Plus 384 plate reader (Sunnyvale, CA). To account for background contributions to sample absorbance values, the absorbance value for the sample replicate without vanillin was subtracted from the replicate that contained vanillin. Quantification was based on a point-to-point calibration curve generated using $0,50,100,250,500$, and $750 \mathrm{mg} / \mathrm{L}$ of catechin hydrate in $80 \%$ $\mathrm{MeOH}$ in water $(\mathrm{v} / \mathrm{v})$. Limits of detection and quantitation were determined empirically to be $2 \mathrm{mg} / \mathrm{L}$ and $8 \mathrm{mg} / \mathrm{L}$, respectively. Samples with absorbance values corresponding to $2 \mathrm{mg} / \mathrm{L}$ catechin hydrate were reported as zero concentration. Samples with absorbance values in excess of the $750 \mathrm{mg} / \mathrm{L}$ standard were diluted using 80:20 methanol: water and reanalyzed. Results were reported in milligrams of catechin equivalents per gram of dried sample.

2.5.9. Carotenoids. $1.5000 \mathrm{~g} \pm 0.0020$ of fresh puree or $0.500 \mathrm{~g} \pm 0.001$ of ground sample was weighed into a $30 \mathrm{~mL}$ FEP centrifuge (Thermo Scientific Nalgene, Rochester, NY) tube. $15 \mathrm{~mL}$ of extraction solution $(200 \mathrm{mg} / \mathrm{L}$ BHT in acetone: ethanol $(50: 50)$ ) was added to the tube and vortexed for $1 \mathrm{~min}$ at speed \#5 (Multi-Tube Vortexer, VWR Scientific, USA). The resulting suspension was clarified by centrifugation at $27,000 \mathrm{~g}$ for $15 \mathrm{~min}$ at $4^{\circ} \mathrm{C}$. The supernatant was collected in a $100 \mathrm{~mL}$ volumetric flask wrapped with foil paper. The pellet was resuspended, and the extraction was repeated twice more. The collected extracts' volume was brought up to a volume of $100 \mathrm{~mL}$ using extraction solution. In a $250 \mathrm{~mL}$ separatory funnel wrapped with foil, the extract was combined with $50 \mathrm{~mL}$ of hexanes and the flask shaken for $1 \mathrm{~min}$. After $15 \mathrm{~min}, 25 \mathrm{~mL}$ of filtered water was added, the flask shaken for $1 \mathrm{~min}$, and the flask left to sit for $30 \mathrm{~min}$ for the separation of the phases. A portion of the carotenoid containing hexane phase was transferred to a glass test tube and the absorbance at $470 \mathrm{~nm}$ measured using a SpectraMax Plus 384 spectrophotometer (Molecular Devices, Sunnyvale, CA, USA). Quantification of total carotenoids was based on the $\beta$-carotene standard calibration curve $(0.1-50.0 \mathrm{mg} / \mathrm{L})$, and concentrations were reported in micrograms $(\mu \mathrm{g})$ of $\beta$-carotene equivalents per gram of dried sample.

2.6. Sidebar: Sensory Analysis. Hedonic (preference) sensory analysis was performed by a consumer panel during this study. Unfortunately, at 12 panelists per time point, the size of the panel was too small to yield definitive conclusions about the changes in sensory quality of the persimmon chips over time (usually, the minimum consumer panel size for a liking test size ranges from 20 to 150 subjects, depending on the degree of difference among the tested products [20]). There were, however, some interesting preliminary results observed in the sensory data. Hence, this material is presented in the supplemental section "Preliminary Hedonic Sensory Analyses." Further discussion of the sensory results will not be made in the main text. 
2.7. Statistical Approach. Standard least squares modeling was performed in JMP (v14.0.0, SAS Institute, Inc., Cary, NC, USA) in order to determine the significance of the main effects (Time, Preparation, and Packaging) and the $2^{\text {nd }}$ - and $3^{\text {rd }}$-order interactions on each response variable. Effects were considered significant at $p<0.05$. For significant effects, Tukey's HSD (honestly significant difference) test was applied to determine which levels of the variable were significantly different from each other. If an interaction term was deemed significant, but one or more of the component main effects were not significant, the significance of the interaction was noted but not explored further with a Tukey's HSD test.

The time-dependent degradation of selected chemical compounds was modeled by the first-order reaction:

$$
\frac{\mathrm{d}[X]}{\mathrm{d} t}=-k[X]
$$

where $[X]$ is the concentration of the relevant compound, $t$ is the time in weeks, and $k$ is the reaction rate constant. Integrating equation (4) leads to a degradation curve of the form

$$
[X]=a e^{-k t},
$$

where $a$ and $k$ are estimable parameters. The nonlinear curve fitting tool was used in JMP to estimate $a$ and $k$ based on available data for $[X]$ vs. $t$. Goodness of fit of the 2-parameter exponential model to the experimental data was characterized by coefficient of determination $\left(R^{2}\right)$ and root mean of square error (RMSE), with the latter defined as follows:

$$
\mathrm{RMSE}=\sqrt{\frac{1}{n-1} \sum_{i=1}^{n}\left(\left[X_{\text {pred }}\right]-\left[X_{\exp }\right]\right)^{2}} \text {, }
$$

where $\left[X_{\text {pred }}\right]$ is the predicted concentration, $\left[X_{\text {exp }}\right]$ is the experimental concentration, and $n$ is the number of data. Higher $R^{2}$ values and lower RMSE values indicate better fitting of the model to the experimental data.

\section{Results and Discussion}

3.1. Overall Trends in Response Variables. Table 2 summarizes the statistical significances of the model effects on the measured variables. From Table 2, it can be noted that Packaging type (Plastic vs. Met-PET) had a significant effect on only 8 of the 31 response variables. These were moisture content and the chemical measurements \% tannins, condensed tannins, carotenoids, and all 4 of the measured organic acids; the specific effects of packaging type on these variables will be discussed in a later section. In general, the lack of an effect of packaging type on most of the quality metrics is a promising finding; it indicates that both consumers and commercial processors can preserve the quality of dried persimmon chips with relatively simple plastic ziptop bags and thus, that specialized packaging material or desiccant packets are not required.

In contrast to Packaging, Preparation had a significant effect on the majority of the response variables. Of all the response variables, only color $\Delta \mathrm{E}$ value, citric acid, and glucose did not depend on Preparation. This is also an expected result, since the two Preparation styles were deliberately quite different; they were intended to produce persimmon chips with different texture properties to cater to consumers with a preference for either moist/chewy or dry/ crispy dried fruit products.

3.2. Moisture-Related Properties. Initial wet basis moisture content $/ a_{\mathrm{W}}$ of the persimmon chips were $8.5 \% / 0.38$ for Preparation 2-5 and 11.2\%/0.48 for Preparation 6-10. Figure 1 depicts the moisture content and $a_{\mathrm{W}}$ of the persimmon chip samples over the time course of the study.

Although there were statistically significant $(p<0.05)$ effects of Time, Packaging, and the Time $*$ Packaging interaction on moisture content, as can be seen from Figure 1, the magnitude of these effects was quite small compared to that of Preparation. Also, there was no clear and consistent pattern for the effects of Time and Packaging on moisture content. Packaging did not have a significant effect on $a_{\mathrm{W}}$. Both preparations experienced a $\sim 0.05$ point net increase in $a_{\mathrm{W}}$ over the 1-year course of the study, with some minor fluctuations at intermediate time points. All samples maintained an appropriately low $(<0.6) a_{\mathrm{W}}$ throughout the entire study. A $a_{\mathrm{W}}$ of 0.6 or lower is recommended to inhibit the growth of yeast and mold in dried foods [21].

3.3. Color. Complete color data are provided in Supplemental Figure 1. In summary, there was a slight decrease in all three basic color values $\left(L^{*}, a^{*}\right.$, and $\left.b^{*}\right)$ over time. Preparation had a more pronounced effect than Time, with the Preparation 2-5 having higher $L^{*}$ and $b^{*}$ values (more lightness and more yellowness) than the Preparation 6-10 and maintaining these higher values over time. Perhaps of greater interest than the absolute color values is $\Delta E$, which is the deviation of the color of the product from the color at Time 0 . At a mean of 8.5 (unitless) for Preparation 2-5 and 8.2 for Preparation 6-10, $\Delta E$ was low for both preparations and did not differ significantly between the preparations. $\Delta E$ increased slightly over time, with the Preparation 2-5 having a greater $\Delta E$ than did the Preparation 6-10 at the 52-week mark (15.0 vs. 9.9).

3.4. Microbiology. Although both Time and Preparation had a significant effect on aerobic bacteria plate count (ABPC) and yeast and mold plate count (YMPC) (Table 2), for both preparations, there was less than a 1-log change in these values between Time 0 and the 1 -year mark. This can be seen in Figure 2.

With some exceptions, Preparation 6-10 had higher microbial counts than did Preparation 2-5. This could be attributed to the greater surface area of the $6 \mathrm{~mm}$ thick slice vs. that of the $2 \mathrm{~mm}$ thick slice, especially the area of the skin, which ringed each slice. Since the native microflora would be located primarily on the exterior of the fruit, slices with greater skin-to-flesh ratio would be expected to have a higher microbial load. Besides the effect of the skin area to this 









(a)

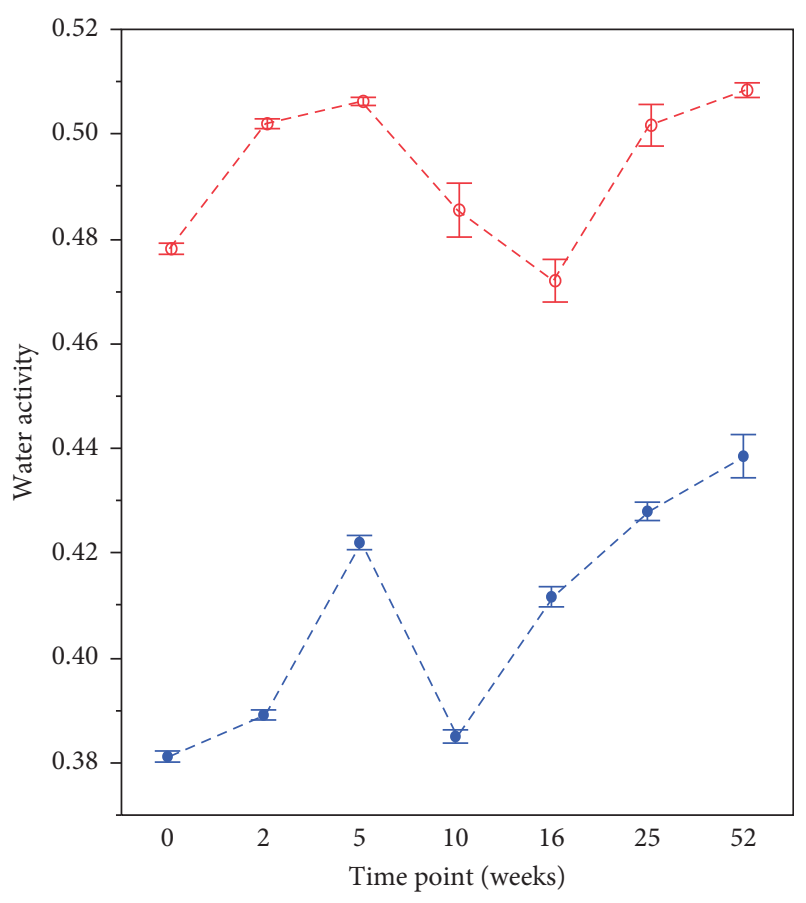

Preparation

$2-5$

○-10

(b)

Figure 1: Mean (a) moisture content and (b) water activity of the persimmon chips over the 1-year course of the storage study. Packaging had a significant $(p<0.05)$ effect on moisture content, so this variable is split out in panel (a). However, Packaging did not have a significant effect on water activity, so Packaging is not specified in panel (b). Each error bar is constructed using 1 standard error from the mean.

trend, it is likely that a greater $a_{\mathrm{W}}$ of the thicker slices throughout the drying period may have been more conducive to microbial survival. The trend is more noticeable for YMPC than for ABPC, since filamentous fungi do not require free surface moisture for growth, whereas bacterial cells do. The difference of 1.4-log in YMPC between the two preparations at the final sampling of 52 weeks is indicative of this trend and may suggest also that the best microbial quality of the dried product as Preparation 6-10 was sustained throughout at least the first 25 weeks of storage, whereas the microbial quality of the chips as Preparation 2-5 remained high throughout the entire storage. It remains unclear why the ABPC at week 10 for Preparation 6-10 was unusually high.

Neither the ABPC nor the YMPC exceeded $10^{3} \mathrm{CFU}$ per chip at any point during the study. Given that individual chips of Preparations 2-5 and 6-10 weighed on average 2 and $6 \mathrm{~g}$, respectively, this places the persimmon chips well within the acceptable range for microbial load in published quality standards which specify that mesophilic aerobic bacteria should be below $10^{5} \mathrm{CFU} / \mathrm{g}$ (Ireland, Israel) and molds below $10^{2} \mathrm{CFU} / \mathrm{g}$ (Israel) in similar dried fruit products [22]. As was expected based on the different $a_{\mathrm{w}} \mathrm{s}$ of the products, the dried persimmon chips in this study exhibited much lower microbial loads than those observed in semidried persimmons with $a_{\mathrm{w}} \mathrm{s}$ in the range of $0.77-0.83$ [9].
3.5. Instrumental Texture. Preparation had a strong effect on all of the instrumental texture variables, with Preparation 6-10 exhibiting a generally harder, tougher, and chewier texture than did Preparation 2-5. Table 3 lists the mean values of the instrumental texture variables for each Preparation.

Time had a significant effect on the TPA attributes Hardness1, Energy1, Hardness2, and Chewiness. Plots of these attributes vs. time can be found in Supplemental Figure 2. Both preparations experienced minor decreases in these attributes in the early weeks of the study. After 10 weeks, Preparation 6-10 saw its already large values continue to increase greatly over time, while Preparation $2-5$ saw minor increases that resulted in no net change in these texture attributes when comparing the 52-week samples to those at Time 0 . In other words, for these 4 texture attributes, chips of Preparation 2-5 largely remained constant (and low) while those of Preparation 6-10 began high and rose even higher after 10 weeks of storage.

3.6. Chemical Analyses. Preparation had a significant effect on all the chemical measurements except citric acid and glucose. Table 4 summarizes the mean values of the chemical measurements for the two preparations. 




Figure 2: Mean microbial load of the persimmon chips over the 1-year course of the storage study. The mean was calculated from the logtransformed plate counts per slice from both packaging types. Each error bar is constructed using 1 standard error from the mean. $\mathrm{CFU}=$ colony-forming units.

TABLE 3: Instrumental texture variables.

\begin{tabular}{|c|c|c|c|}
\hline \multirow{2}{*}{ Texture analysis type } & \multirow{2}{*}{ Variable } & \multicolumn{2}{|c|}{ Preparation } \\
\hline & & $2-5$ & $6-10$ \\
\hline \multirow{8}{*}{ Texture profile analysis (TPA) } & Hardness1 (N) & $36.02 \pm 1.57^{* * *}$ & $108.02 \pm 2.86^{* * *}$ \\
\hline & Energyl $(\mathrm{N} \cdot \mathrm{mm})$ & $3.27 \pm 0.19^{* * *}$ & $24.92 \pm 0.85^{* * *}$ \\
\hline & Hardness2 (N) & $33.00 \pm 1.49^{* * *}$ & $89.85 \pm 2.77^{* * *}$ \\
\hline & Energy2 $(\mathrm{N} \cdot \mathrm{mm})$ & $2.17 \pm 0.13^{* * *}$ & $14.02 \pm 0.66^{* * *}$ \\
\hline & Cohesiveness ( ) & $0.666 \pm 0.016^{* * *}$ & $0.561 \pm 0.014^{* * *}$ \\
\hline & Springiness ( ) & $0.730 \pm 0.011^{* * *}$ & $0.656 \pm 0.012^{* * *}$ \\
\hline & Chewiness $(\mathrm{N})$ & $17.90 \pm 0.94^{* * *}$ & $41.36 \pm 2.26^{* * *}$ \\
\hline & Resilience ( ) & $0.731 \pm 0.022^{* * *}$ & $0.448 \pm 0.016^{* * *}$ \\
\hline \multirow{3}{*}{ Shear } & MaxLoad (N) & $26.66 \pm 1.19^{* * *}$ & $51.79 \pm 1.38^{* * *}$ \\
\hline & Toughness $(\mathrm{N} \cdot \mathrm{mm})$ & $37.47 \pm 2.69^{* * *}$ & $107.18 \pm 3.48^{* * *}$ \\
\hline & PeakCount ( ) & $6.49 \pm 0.48^{* *}$ & $9.54 \pm 0.93^{* *}$ \\
\hline
\end{tabular}

Listed values are mean (for all tested time points) \pm 1 standard error from the mean. ${ }^{* *}$ Significant difference between preparations at $p<0.01 ;{ }^{* * *}$ significant difference between preparations at $p<0.001$. ( ) $=$ unitless.

3.6.1. Phenolic Compounds, Antioxidant Activity, and Tannins. Supplementary Figure 3 depicts the changes in total soluble phenolic compounds (TSP) and antioxidant activity (AOX) over time. Figure 3 depicts these data for $\%$ tannins and condensed tannins.

Preparation 2-5 generally had higher levels of total soluble phenolic compounds (TSP), antioxidant activity (AOX), \% tannins, and condensed tannins than did Preparation $6-10$. The exception to this trend was that the two preparations started with approximately equal levels of $\%$ tannins at Time 0 . The high levels of phenolic compounds (especially tannins) in Preparation 2-5 should be investigated for their impact on the astringency of the product. AOX and TSP are known to decrease in persimmons during hot-air-drying [23], and in this study, we have seen evidence that the length of drying treatment has a strong effect on these parameters. Both preparations were dried at the same temperature $\left(63^{\circ} \mathrm{C}\right)$, but Preparation $6-10$ was in the 
TABle 4: Chemical analysis variables.

\begin{tabular}{|c|c|c|c|}
\hline \multirow{2}{*}{ Chemical analysis type } & \multirow{2}{*}{ Variable } & \multicolumn{2}{|c|}{ Preparation } \\
\hline & & $2-5$ & $6-10$ \\
\hline \multirow{4}{*}{ Phenolics, antioxidant activity, tannins } & AOX (mg TEAC/g DW) & $25.49 \pm 1.07^{* * *}$ & $6.91 \pm 0.34^{* * *}$ \\
\hline & TSP (mg GAE/g DW) & $14.74 \pm 0.26^{* * *}$ & $4.76 \pm 0.11^{* * *}$ \\
\hline & $\%$ tannins & $66.80 \pm 2.67^{* * *}$ & $13.79 \pm 1.42^{* * *}$ \\
\hline & Condensed tannins (mg CE/g DW) & $15.27 \pm 0.65^{* * *}$ & $1.98 \pm 0.20^{* * *}$ \\
\hline \multirow{4}{*}{ Organic acids } & Ascorbic acid $(\mu \mathrm{g} / \mathrm{g} \mathrm{DW})$ & $458.0 \pm 30.1^{* * *}$ & $393.8 \pm 49.0^{* * *}$ \\
\hline & Malic acid $(\mu \mathrm{g} / \mathrm{g}$ DW $)$ & $8189 \pm 77^{* *}$ & $8007 \pm 121^{* *}$ \\
\hline & Citric acid $(\mu \mathrm{g} / \mathrm{g} D W)$ & $7165 \pm 143$ & $7065 \pm 225$ \\
\hline & Fumaric acid $(\mu \mathrm{g} / \mathrm{g}$ DW $)$ & $168.7 \pm 2.5^{* * *}$ & $116.4 \pm 4.4^{* * *}$ \\
\hline \multirow{3}{*}{ Sugars } & Fructose $(\mathrm{g} / \mathrm{kg} \mathrm{DW})$ & $140.0 \pm 1.9^{*}$ & $141.1 \pm 5.0^{*}$ \\
\hline & Glucose (g/kg DW) & $149.7 \pm 2.0$ & $147.8 \pm 4.2$ \\
\hline & Sucrose (g/kg DW) & $368.8 \pm 4.6^{* * *}$ & $343.9 \pm 12.6^{* * *}$ \\
\hline Carotenoids & Carotenoids $(\mu \mathrm{g} \beta$-CE/g DW) & $415.6 \pm 15.3^{* * *}$ & $369.7 \pm 12.0^{* * *}$ \\
\hline
\end{tabular}

Listed values are mean (for all tested time points) \pm 1 standard error from the mean. ${ }^{*}$ Significant difference between preparations at $p<0.05$; ${ }^{* *}$ significant difference between preparations at $p<0.01 ; * * *$ significant difference between preparations at $p<0.001$. AOX $=$ antioxidant activity; TEAC $=$ Trolox equivalent antioxidant capacity; DW = dry weight; TSP = total soluble phenolics; GAE = gallic acid equivalents; $\mathrm{CE}=$ catechin equivalents; $\beta$-CE $=\beta$-carotene equivalents.

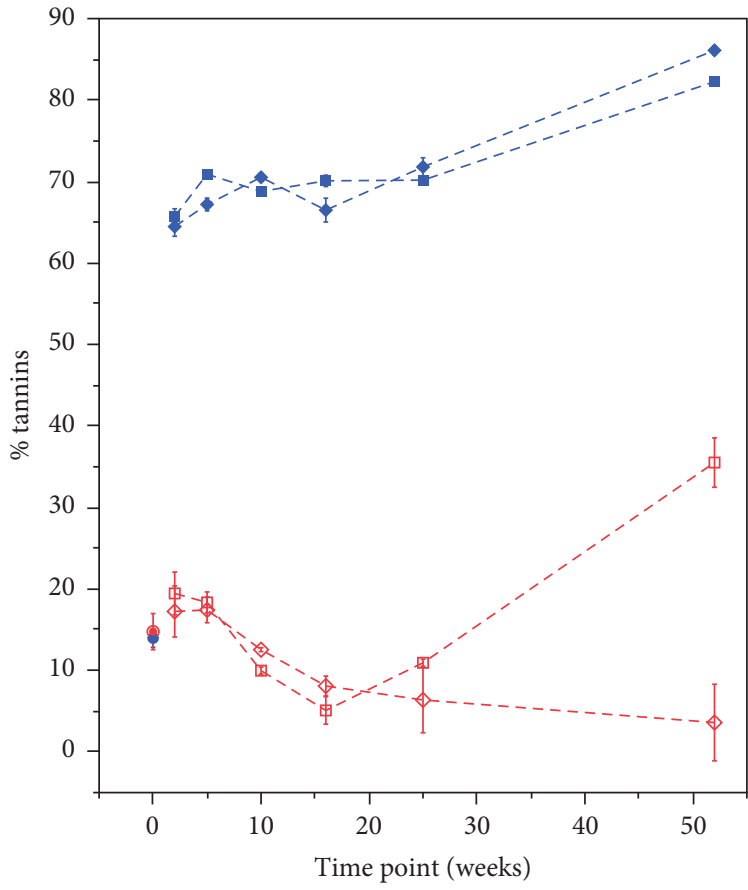

Preparation, packaging

\begin{tabular}{ll}
$-2-5$ & $\bigcirc 6-10$ \\
$2-5$, Met-PET & $\diamond 6-10$, Met-PET \\
\hline 2-5, Plastic & $\square 6-10$, Plastic
\end{tabular}

(a)

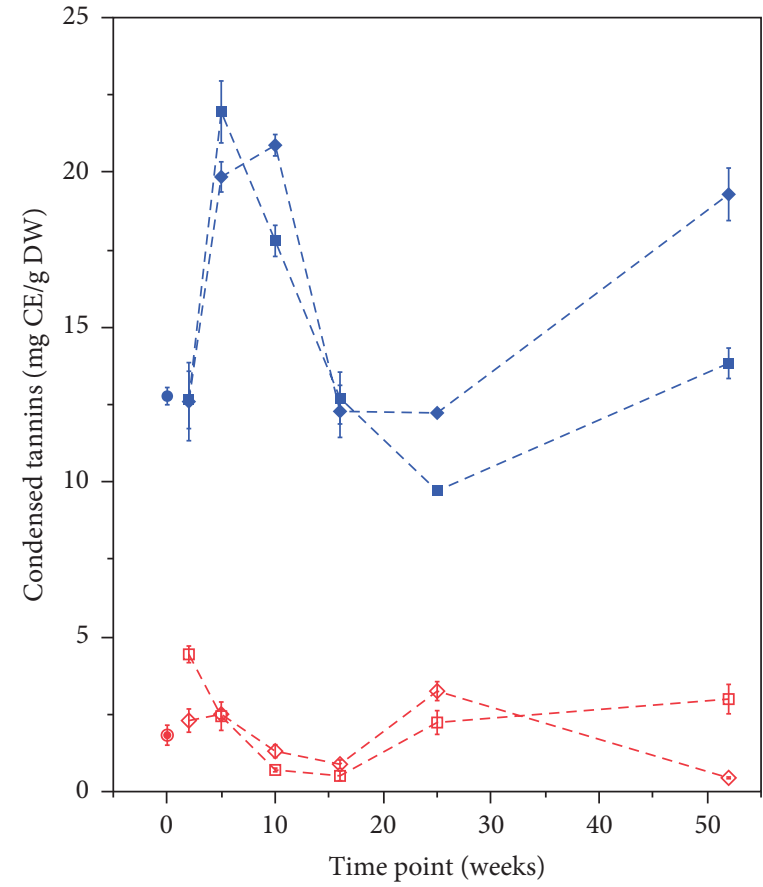

Preparation, packaging
- 2-5
O $6-10$
2-5, Met-PET
$\diamond 6-10$, Met-PET
2-5, Plastic
$\square$ 6-10, Plastic

(b)

Figure 3: Mean levels of the (a) \% tannins and (b) condensed tannins of the persimmon chips over the 1-year course of the storage study. Each error bar is constructed using 1 standard error from the mean. CE = catechin equivalents; DW = dry weight.

dehydrators for twice as long as Preparation 2-5. It is notable that Preparation 6-10 had lower levels of healthy antioxidant compounds than did Preparation 2-5. This is similar to the result of Chung et al. [24], who found that applying a deastringency process to persimmons before drying decreased antioxidant activity.
The $\%$ tannins and condensed tannins were some of the few variables in this study which exhibited a significant dependence on Packaging type. However, compared to the effect of Preparation, the magnitude of this effect was small, and it was driven by differences observed at the 52-week time point. In particular, at the final time point of the study, the 
Plastic-packaged Preparation 6-10 samples exhibited higher $\%$ tannins and condensed tannins than their Met-PETpackaged counterparts (see Figure 3). However, the Preparation 2-5 samples showed the opposite pattern (Met-PET higher than Plastic at 52 weeks). Hence, as was the case for moisture content, an effect of Packaging was observed, but the small magnitude and inconsistent presentation of this effect mean that it is of less interest than the effect of Preparation.

3.6.2. Organic Acids. Figure 4 depicts the change in ascorbic acid (vitamin C) over the year-long study; the analogous data for the other organic acids (malic, citric, and fumaric) are presented in Supplemental Figure 4.

Compared to Preparation 6-10, Preparation 2-5 had higher average levels of all the measured organic acids except citric acid. Similar to the degradation of phenolic compounds, ascorbic, malic, and fumaric acid apparently experienced a degradation during hot-air-drying that was more pronounced in the longer-processed treatment (Preparation 6-10). Regarding the effect of Time, levels of malic, citric, and fumaric acid fluctuated over the course of the study but, on net for a given Preparation, did not exhibit significant differences between values at Time 0 and 52 weeks. In contrast, ascorbic acid experienced a steady exponential decline over time, as depicted in Figure 4 . The overall 1-year decrease in ascorbic acid ranged from $78.0 \%$ to $96.5 \%$, depending on the particular Preparation/Packaging combination. This is an unfortunate result but is in line with the behavior of ascorbic acid in other dried fruits. Latapi and Barrett, for example, found ascorbic acid losses of $82 \%-97 \%$ after only 3 months of $25^{\circ} \mathrm{C}$ storage for sun-dried tomatoes subjected to various sulfur and salt predrying treatments [25]. Del Caro et al. observed ascorbic acid in 2 varieties of dried prune decrease to about half of its original level after 12 months of storage at $20^{\circ} \mathrm{C}$ [26].

At 2 weeks, ascorbic acid was actually higher in Preparation 6-10 than in Preparation 2-5; this is contrary to the previously discussed general trend that ascorbic acid was higher in the shorter-processed product (Preparation 2-5). The high uncertainty in the measurement at Time 0 and the large difference in the effect of Packaging at only 2 weeks (when no such difference was seen for Preparation 2-5) suggest that this was more a result of biological variability among the samples than of any real effect of the Preparation. In any case, after 2 weeks, ascorbic acid declined sharply in Preparation 6-10 and more moderately in Preparation 2-5. The declines fit well to a first-order kinetics model; overlay lines and goodness-of-fit metrics are shown in Figure 5. This agrees well with the degradation pattern observed for ascorbic acid in a variety of other food products during storage [27]. The significant effect of Packaging for this variable was that ascorbic acid in the Met-PET-packaged samples was generally higher than that of the Plasticpackaged samples. As can be seen in Figure 4, though, this effect was small in magnitude compared to the effects of Time and Preparation.
3.6.3. Sugars. For both preparations, initial sucrose levels were 2 to 3 times higher than those of glucose and fructose. Levels of all 3 sugars remained fairly constant for Preparation 2-5, but Preparation 6-10 saw dramatic changes in the sugar levels in the second half of the study. This is depicted in Figure 5.

The hydrolysis of sucrose into its component monosaccharides glucose and fructose is facilitated by the action of the enzyme invertase, which is known to have high activity in persimmons [28]. Examination of the Preparation 6-10 data in Figure 5 shows the decrease in sucrose and concomitant increase in glucose and fructose that would be expected for this reaction. Thus, the results of this study indicate that invertase activity was quenched in Preparation 2-5 but not in Preparation 6-10. This is unexpected for two reasons. Firstly, Preparation 6-10 ostensibly had the harsher (2x longer drying time) drying treatment, so enzyme activity would be expected to be lower in this Preparation. Secondly, it is known that, for intact persimmons dried over several days at ambient temperature, hand-massaging the fruit (i.e., causing moderate mechanical damage) encourages the conversion of sucrose to glucose and fructose, vs. an unmassaged control [29]. However, in this study, the greater mechanical damage to the Preparation 2-5 samples during slicing (thinner slice resulting in relatively more damaged cells) apparently did not result in increased sucrose hydrolysis, compared to the relatively less damaged Preparation 6-10 chips. One possible explanation for the observed phenomenon is that, although the moisture content and $a_{\mathrm{W}}$ of both preparations were quite low, the Preparation 6-10 samples nevertheless were higher than the Preparation 2-5 samples for these metrics. Therefore, invertase activity may have been slightly higher for the more moist/higher $a_{\mathrm{W}}$ Preparation. Furthermore, invertase activity may have been preserved better in the protected interior of the Preparation 6-10 chips. Such spatial resolution of enzyme activity is an interesting topic but beyond the scope of this study.

3.6.4. Carotenoids. Carotenoids experienced a pattern of degradation over time that was similar to that of ascorbic acid. Also analogous to ascorbic acid content, carotenoid content was significantly affected by Time, Preparation, Packaging, and several higher-order interaction terms. Thus, degradation of carotenoids was modeled as first-order kinetic reaction, specific to a given Preparation/Packaging combination. This is depicted in Figure 6.

Degradation of carotenoids in dried foods during storage has been characterized by first-order kinetics for both carrot [30] and orange-fleshed sweet potato [31]. The results of this study indicate that a similar first-order reaction occurs in hot-air-dried persimmon. In summary, carotenoid content decreased to roughly half of its initial value by the end of the year-long study. The generally higher levels of carotenoids in Preparation 2-5 coincide with this Preparation's higher yellow color (higher $b^{*}$ value), compared to that of Preparation 6-10. With the exception of the 52-week measurement of the Preparation 2-5 samples, Plastic packaging yielded higher carotenoid content than did Met-PET 


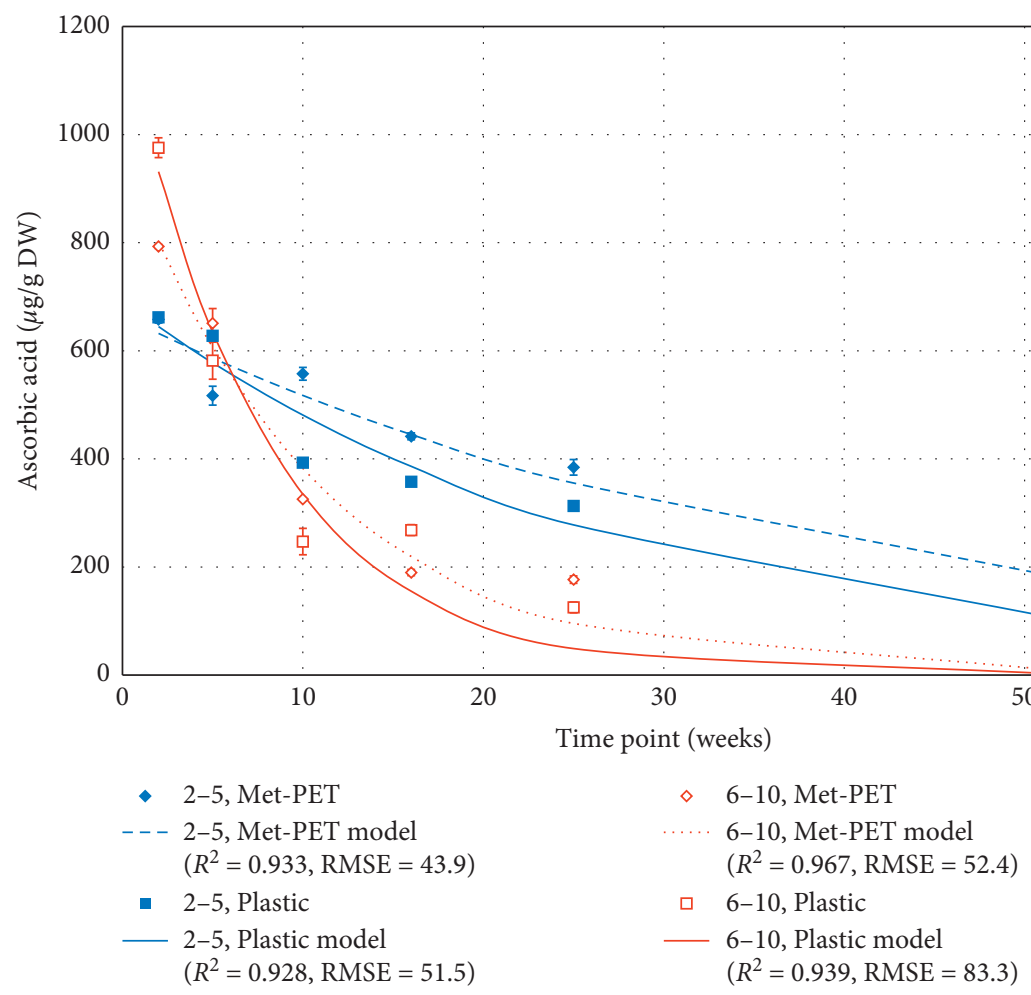

FIGURE 4: Mean levels of ascorbic acid of the persimmon chips over the 1-year course of the storage study, overlaid with best-fit exponential decay ( $1^{\text {st }}$-order kinetics) curves. Each error bar is constructed using 1 standard error from the mean. DW $=$ dry weight.

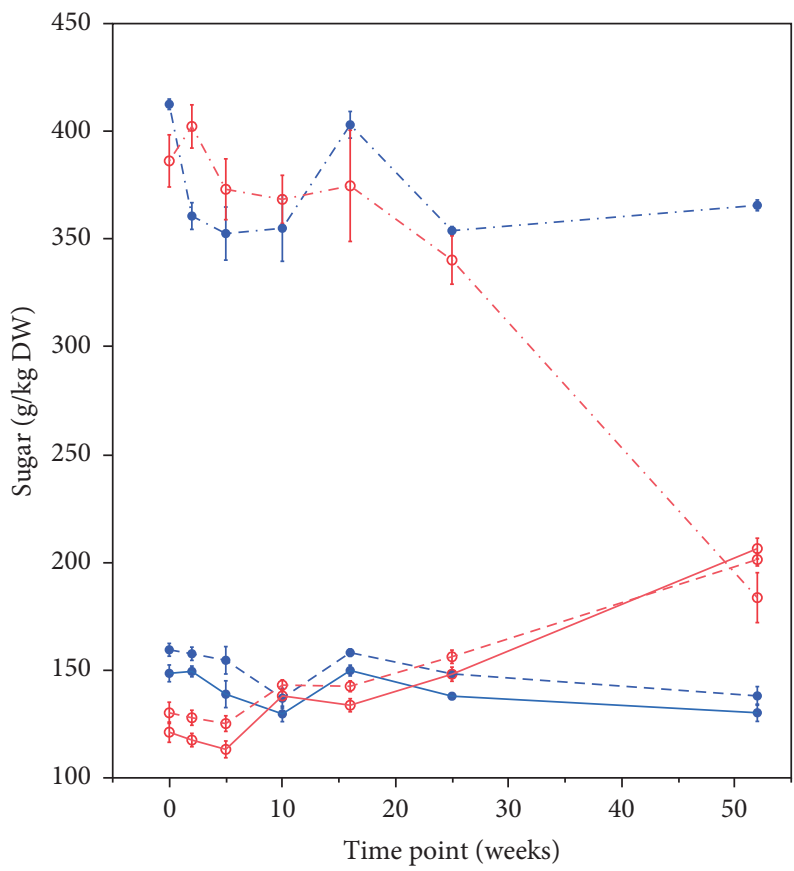

Sugar, Preparation

- - - Sucrose, $2-5$

- - Glucose, $2-5$

-..- Sucrose, 6-10

- Fructose, 2-5

- - Glucose, 6-10

— Fructose, 6-10

Figure 5: Mean levels of 3 sugars in the persimmon chips over the 1-year course of the storage study. Each error bar is constructed using 1 standard error from the mean. DW=dry weight. 


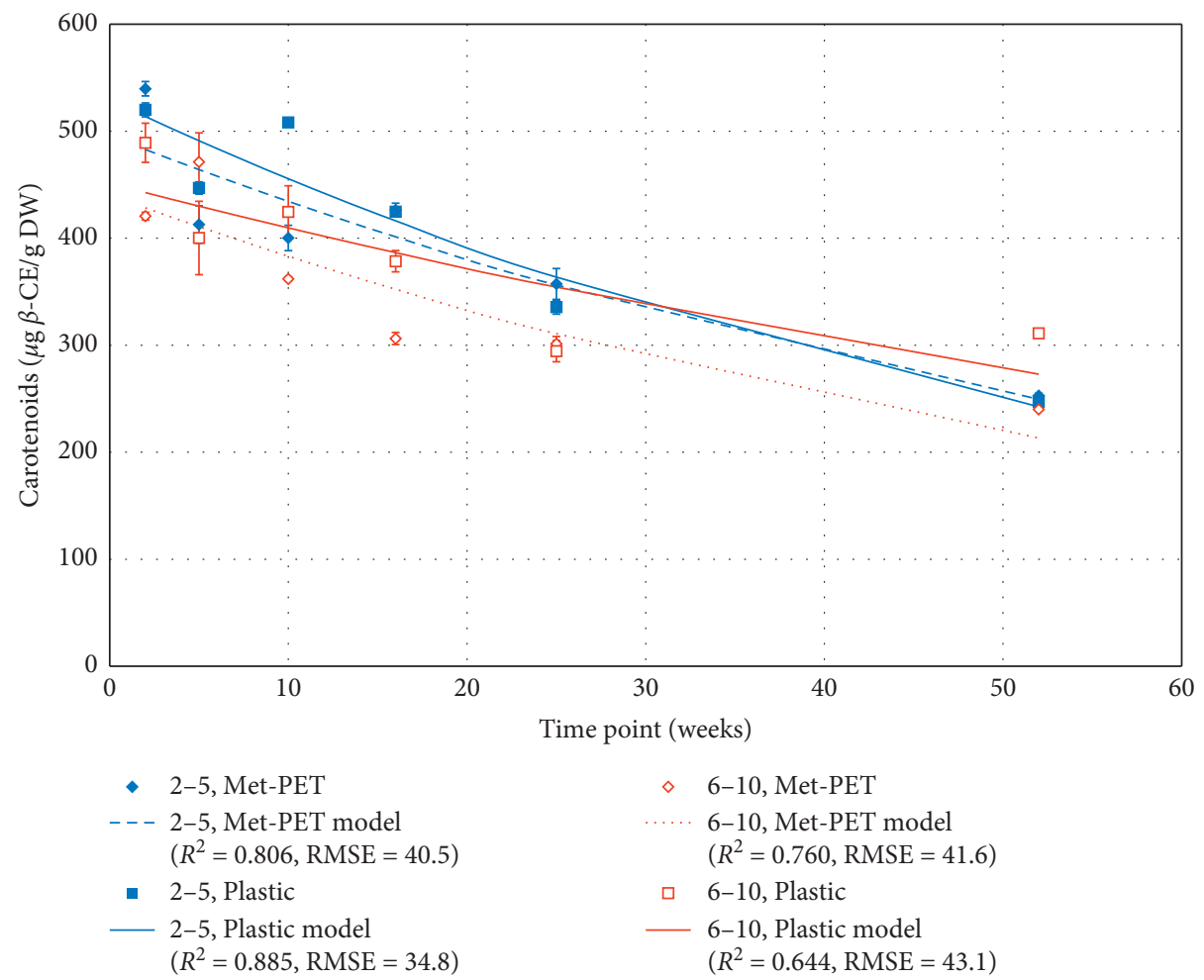

Figure 6: Mean levels of carotenoids of the persimmon chips over the 1-year course of the shelf-life study, overlaid with best-fit exponential decay $\left(1^{\text {st }}\right.$-order kinetics) curves. Each error bar is constructed using 1 standard error from the mean. $\beta$-CE $=\beta$-carotene equivalents; DW = dry weight.

packaging. The magnitude of this effect was small, however, compared to the effects of Time and Preparation.

\section{Conclusions}

Hot-air-dried persimmon chips maintained acceptable color, microbial, textural, and nutritional quality throughout the entire 1-year storage study. The exception to this statement is that ascorbic acid decreased greatly $(78.0 \%$ to $96.5 \%$ ) over 12 months of storage; this decrease is not unusual for a dried fruit product of this type, though. Compared to Preparation 2-5 chips, Preparation 6-10 chips generally had lower contents of healthy nutrients-antioxidant compounds, ascorbic acid, and carotenoids. However, the impact of these nutrients (some of which may be quite astringent) on the flavor and mouthfeel of the nutrients should be explored. For both preparations, the contents of the sensitive nutritional components ascorbic acid and carotenoids experienced time-dependent decreases; this is typical for preserved fruit products but should be taken into account when developing nutritional content claims for the dried chip product. Plastic zip-top bags and Met-PET bags with desiccant packets performed equally well as packaging for most of the quality metrics tracked during this study. However, it should be noted that, in this study, all bags were stored in the dark in an enclosed secondary container, and light-sensitive components may not fare as well in plastic zip-top bags on exposed shelves or counters. Overall, this work has demonstrated that hot-air- drying of persimmon slices is a promising approach to create a value-added product with at least 1 year of shelf-life.

\section{Data Availability}

The data used to support the findings of this study are available from the corresponding author upon request.

\section{Conflicts of Interest}

The authors declare that there are no conflicts of interest regarding the publication of this paper.

\section{Acknowledgments}

The work described herein was supported by the United States Department of Agriculture-Agricultural Research Service appropriated projects 2030-41000-064-00D, 203041440-007-00D, and 2030-42000-050-00D.

\section{Supplementary Materials}

Supplemental Figure 1: mean (a) $L^{*}$, (b) $a^{*}$, (c) $b^{*}$, and (d) $\Delta E$ color measurements of the persimmon chips over the 1year course of the storage study. Each error bar is constructed using 1 standard error from the mean. Supplemental Figure 2: mean (a) texture profile analysis (TPA) Hardness1, (b) Energy1, (c) Hardness2, and (d) Chewiness measurements of the persimmon chips over the 1-year course of the storage study. Each error bar is constructed 
using 1 standard error from the mean. Supplemental Figure 3: mean (a) total soluble phenolics (TSP) and (b) antioxidant activity (AOX) of the persimmon chips over the 1 -year course of the storage study. Each error bar is constructed using 1 standard error from the mean. DW= dry weight, $\mathrm{GAE}=$ gallic acid equivalents, $\mathrm{TEAC}=$ Trolox equivalents. Supplemental Figure 4: mean (a) malic, (b) citric, and (c) fumaric acid content of the persimmon chips over the 1-year course of the storage study. Each error bar is constructed using 1 standard error from the mean. DW $=$ dry weight. Supplemental Figure 5: mean sensory hedonic ratings of the (a) overall, (b) appearance, (c) texture, and (d) taste/flavor attributes of the persimmon chips over the 1-year course of the storage study. Each error bar is constructed using 1 standard error from the mean. Supplemental Table 1: statistical significance of main effects and interactions on the consumer sensory liking of the product. *Significant with $p<0.05 ;{ }^{* *}$ significant with $p<0.01$; *** significant with $p<0.001$. (Supplementary Materials)

\section{References}

[1] UN Production/Crops, Persimmons, Food and Agriculture Organization Corporate Statistical Database (FAOSTAT), 2019.

[2] M. Igual, M. L. Castelló, E. Roda, and M. D. Ortolá, "Development of hot-air dried cut persimmon," International Journal of Food Engineering, vol. 7, no. 5, 2011.

[3] R. R. Milczarek, R. D. Woods, S. I. LaFond et al., "Synthesis of descriptive sensory attributes and hedonic rankings of dried persimmon (Diospyros kaki sp.)," Food Science \& Nutrition, vol. 6, no. 1, pp. 124-136, 2018.

[4] Y. Jia, I. Khalifa, L. Hu et al., "Influence of three different drying techniques on persimmon chips' characteristics: a comparison study among hot-air, combined hot-air-microwave, and vacuum-freeze drying techniques," Food and Bioproducts Processing, vol. 118, pp. 67-76, 2019.

[5] C. Perera, "Selected quality attributes of dried foods," Drying Technology, vol. 23, no. 4, pp. 717-730, 2005.

[6] A. Stešková, M. Morochovičová, and E. Lešková, "Vitamin C degradation during storage of fortified foods," Journal of Food and Nutrition Research, vol. 45, no. 2, pp. 55-61, 2006.

[7] Y.-Y. Jia, S. J. Zhou, and C.-M. Li, "Comparison of different packaging methods on the quality of persimmon chips stored at constant temperature," Modern Food Science and Technology, vol. 34, no. 10, pp. 196-204, 2018.

[8] A. Sugiura and S. Taira, "Dried persimmon production in Japan," Acta Horticulturae, vol. 833, no. 833, pp. 71-76, 2009.

[9] J. Hyun, J. Kim, E. Kim, J. Kim, and S. Lee, "Changes in microbiological and physicochemical quality of dried persimmons (Diospyros kaki thunb.) stored at various temperatures," Journal of Food Quality, vol. 2019, Article ID 6256409, 9 pages, 2019.

[10] How to Dry California-Grown Persimmons, 2017.

[11] N. Thakur, S. Sharma, V. K. Joshi, K. S. Thakur, and N. Jindal, "Studies on drying, packaging and storage of solar tunnel dried Chilgoza nuts," Archives of Applied Science Research, vol. 4, no. 3, pp. 1311-1319, 2012.

[12] C. Henríquez, V. Loewe, J. Saavedra, A. Córdova, and M. Lutz, "Effect of the type of packaging on the oxidative stability of pine nuts (Pinus pinea L.) grown in Chile," CyTA-Journal of Food, vol. 16, no. 1, pp. 255-262, 2018.
[13] Sorbent Systems, "Desiccant packets," 2019, https://www. sorbentsystems.com/smallpacketstable.html.

[14] C. W. Olsen, R. Woods, I. Sedej et al., "Texture attributes of a persimmon (Diospyros kaki) chip-style product," in Proceedings of the Poster Presentation at the Institute of Food Technologists (IFT) Annual Meeting, Las Vegas, NV, USA, June 2017.

[15] A. P. Breksa and G. D. Manners, "Evaluation of the antioxidant capacity of limonin, nomilin, and limonin glucoside," Journal of Agricultural and Food Chemistry, vol. 54, no. 11, pp. 3827-3831, 2006.

[16] V. L. Singleton and J. A. Rossi Jr., "Colorimetry of total phenolics with phosphomolybdic-phosphotungstic acid reagents," American Journal of Enology and Viticulture, vol. 16, pp. 144-158, 1965.

[17] P.-W. Wu and L. S. Hwang, "Determination of soluble persimmon tannin by high performance gel permeation chromatography," Food Research International, vol. 35, no. 8, pp. 793-800, 2002.

[18] B. Sun, J. M. Ricardo-da-Silva, and I. Spranger, "Critical factors of vanillin assay for catechins and proanthocyanidins," Journal of Agricultural and Food Chemistry, vol. 46, no. 10, pp. 4267-4274, 1998.

[19] S. Karaman, O. S. Toker, M. Çam, M. Hayta, M. Doğan, and A. Kayacier, "Bioactive and physicochemical properties of persimmon as affected by drying methods," Drying Technology, vol. 32, no. 3, pp. 258-267, 2014.

[20] N. Mammasse and P. Schlich, "Adequate number of consumers in a liking test: insights from resampling in seven studies," Food Quality and Preference, vol. 31, no. 1, pp. 124-128, 2014.

[21] W. D. Grant, "Life at low water activity," Philosophical Transactions of the Royal Society of London. Series B: Biological Sciences, vol. 359, no. 1448, pp. 1249-1267, 2004.

[22] Appendix E: International Microbiological Criteria, in Scientific Criteria to Ensure Safe Food, 2003.

[23] Y.-S. Park, S.-T. Jung, S.-G. Kang et al., "Drying of persimmons (Diospyros kaki L.) and the following changes in the studied bioactive compounds and the total radical scavenging activities," LWT-Food Science and Technology, vol. 39, no. 7, pp. 748-755, 2006.

[24] H.-S. Chung, D.-H. Kim, H.-S. Kim et al., "Quality comparison of dried slices processed from whole persimmons treated with different deastringency methods," Food Science and Biotechnology, vol. 26, no. 2, pp. 401-407, 2017.

[25] G. Latapi and D. M. Barrett, "Influence of pre-drying treatments on quality and safety of sun-dried tomatoes-part I: use of steam blanching, boiling brine blanching, and dips in salt or sodium metabisulfite," Journal of Food Science, vol. 71, no. 1, pp. S32-S37, 2006.

[26] A. Del Caro, A. Piga, I. Pinna, P. M. Fenu, and M. Agabbio, "Effect of drying conditions and storage period on polyphenolic content, antioxidant capacity, and ascorbic acid of prunes," Journal of Agricultural and Food Chemistry, vol. 52, no. 15, pp. 4780-4784, 2004.

[27] M. Peleg, M. D. Normand, W. R. Dixon, and T. R. Goulette, "Modeling the degradation kinetics of ascorbic acid," Critical Reviews in Food Science and Nutrition, vol. 58, no. 9, pp. 1478-1494, 2018.

[28] E. Giordani, S. Doumett, S. Nin, and M. Del Bubba, "Selected primary and secondary metabolites in fresh persimmon (Diospyros kaki Thunb.): a review of analytical methods and current knowledge of fruit composition and health benefits," Food Research International, vol. 44, no. 7, pp. 1752-1767, 2011. 
[29] H. Yamada, T. Ando, K. Tsutani, S. Amano, and Y. Yamamoto, "Mechanism of browning occurring during the processing of semi-dried persimmons," Journal of the Japanese Society for Horticultural Science, vol. 78, no. 1, pp. 124130, 2009.

[30] V. Lavelli, B. Zanoni, and A. Zaniboni, "Effect of water activity on carotenoid degradation in dehydrated carrots," Food Chemistry, vol. 104, no. 4, pp. 1705-1711, 2007.

[31] N. Achir, C. Pénicaud, A. Bechoff, R. Boulanger, M. Dornier, and C. Dhuique-Mayer, "Use of multi-response modelling to investigate mechanisms of $\beta$-carotene degradation in dried orange-fleshed sweet potato during storage: from carotenoids to aroma compounds," Food and Bioprocess Technology, vol. 7, no. 6, pp. 1656-1669, 2014. 